\title{
PERSONA, ESCLAVITUD Y LIBERTAD EN GREGORIO DE NISA
}

\author{
Lucas F. Mateo-Seco \\ Universidad de Navarra
}

\begin{abstract}
RESUMEN
Gregorio de Nisa es uno de los hombres más cultos del IV. Él recoge los avances que tienen lugar en ese siglo sobre el concepto de persona y su relación con la naturaleza. Para Gregorio, la dignidad de la persona humana radica fundamentalmente en el hecho de ser imagen y semejanza de Dios. Esto equivale a afirmar que el hombre está dotado de unos atributos que nadie le debe quitar; entre ellos destaca la libertad que es como la corona de su ser personal, pues está hecho a imagen de Dios, el cual es a-déspotos, es decir, no tiene dueño. El rechazo de la esclavitud, junto con la firma defensa de la parrhesía (la libertad de expresión), constituye una de las perspectivas más adecuadas para calibrar el concepto que tiene Gregorio de la naturaleza humana y de la dignidad del ser personal. Gregorio trata explícitamente este asunto en muchos lugares. Aquí nos limitamos a comentar los más importantes: la Homilía IV Sobre el Eclesiastés, el tratado Sobre el origen del hombre, y el Gran discurso catequéti$c o$. Según Gregorio, la libertad le ha sido dada al hombre para que participe en los bienes divinos. Gregorio se apoya, además, en el pensamiento inspirado en Platón de que la virtud es esencialmente voluntaria y libre y, en consecuencia, que la libertad es un atributo irrenunciable de la dignidad del ser personal.
\end{abstract}

Palabras clave: Gregorio de Nisa, persona humana, antropología, esclavitud, libertad, antropología patrística.

\begin{abstract}
Gregory of Nyssa was one of the most cultivated men of the fourth century. He reflects the advances that had been made concerning the concept of the person and his/her relationship with nature. In Gregory's view, the dignity of the human person is grounded on the fact that the person is the image and likeness of God. This is equivalent to stating that the human being has attributes which no one may deprive him/her of; prominent among these is freedom, which is the crowning glory of his/her personal being, as he/she was made in the image of God, who is a-déspotos, that is, has no master. Rejection of slavery, together with firm defence of parrhesia (freedom of speech), is one of the most suitable perspectives for evaluating Gregory's concept of human nature and the dignity of the person. Gregory discusses this subject explicitly in several places. Here we shall confine our survey to the most important ones: Homily IV On Ecclesiastes, the treatise On the origin of man, and the Great catechetical discourse. According to Gregory, freedom was given to human beings so that they could participate in the divine good. Gregory supported his arguments on the thinking inspired by Plato in which virtue is essentially free and voluntary, and so freedom is an attribute of the dignity of the person that cannot be relinquished.
\end{abstract}

Key words: Gregory of Nyssa, Human person, Anthropology, Slavery, Freedom, Patristic anthropology. 
La personalidad de Gregorio de Nisa atrae con fuerza creciente a los estudiosos de estos últimos sesenta años. Para comprobarlo, basta compulsar los volúmenes dedicados exclusivamente a la bibliografía que existe sobre él, ${ }^{1}$ a los Diccionarios sobre su lenguaje y su pensamiento, ${ }^{2}$ o a los Simposios Internacionales que se le dedican cada cuatro años. ${ }^{3}$ Y es que Gregorio de Nisa es uno de los hombres más cultos del IV. ${ }^{4}$ Él recoge el avance que tiene lugar sobre el concepto de persona y su relación con la naturaleza, primero al servicio de la doctrina sobre la intimidad trinitaria de Dios, y después al servicio de la personalidad y dignidad del hombre. ${ }^{5}$ Gregorio es uno de los filósofos y teólogos más emblemáticos del siglo IV. Y, desde luego, marca la orientación que el mundo occidental tomará a la hora de ir descubriendo el ser y la dignidad de la persona. Incluso, como anota A. Spira al hablar del concepto que Gregorio tiene de progreso, marca también la concepción de un progreso al infinito. ${ }^{6}$

Para Gregorio, como para los demás Padres de la Iglesia, la dignidad de la persona humana radica fundamentalmente en el hecho de ser imagen y semejanza de Dios, que es comunión de tres Personas. Esto equivale a afirmar que el hombre está dotado de unos atributos que nadie le debe quitar; entre ellos destaca la libertad que es como la corona de su ser personal, pues está hecho a imagen de Dios, el cual es a-déspotos, es decir, que no tiene dueño. El rechazo de la esclavitud, junto con la parrhesía (la libertad de expresión), ${ }^{7}$ constituye así una de las

1 La bibliografía más completa y actual es la de M. Altenburger y F. Mann, Bibliographie zu Gregor von Nyssa. Editionen, Übersetzungen, Literatur, Brill, Leiden 1988, 394 pp., cuya segunda edición está a punto de aparecer.

2 Cfr Cajus Fabricius y Daniel Ridings (eds.), A Concordance to Gregory of Nyssa [Microforma], Acta Universitatis Gothoburgensis, Göteborg 1989; Friedhelm Mann (ed.), Lexicon Gregorianum: Wörterbuch zu den Schriften Gregors von Nyssa, Brill, Leiden 1999-2003, cuyos volúmenes llegan ya hasta la letra kappa. Ha aparecido ya en el 2006 en Burgos (Monte Carmelo) y en Roma (Città Nuova) un Diccionario de Gregorio de Nisa con mas de novecientas páginas.

3 Entre ellos destacan Chevetogne 1969 (M. Harl [ed.], Écriture et culture philosophique dans la pensée de Grégoire de Nysse, Brill, Leiden 1971); Münster 1972 (H. Dörrie, M. Altenburger y U. Schramm [eds.], Gregor von Nyssa und die Philosophie, Brill, Leiden 1976); Leiden 1974 (J.C.M. van Winden, A. van Heck [eds.], Colloquii Gregoriani III Leidensis Acta, pro manuscripto); Cambridge 1978 (A. Spira, C. Klock [eds.], The Easter Sermons of Gregory of Nyssa, Cambridge, Massachusetts, 1981); Mainz 1982 (A. Spira [ed.], The Biographical Works of Gregory of Nyssa, Cambridge, Massachusetts 1984); Pamplona 1986 (L.F. Mateo Seco y J.L. Bastero [eds.], El "Contra Eunomium I» en la producción literaria de Gregorio de Nisa, Eunsa, Pamplona 1988); St. Andrews 1990 (St. G. Hall [ed.], Gregory of Nyssa, Homilies on Ecclesiastes. An English Version with Supporting Studies, Walter de Gruyter, Berlín 1993); Paderborn 1998 (H. R. Drobner, A. Viciano [eds.], Gregory of Nyssa, Homilies on the Beatitudes. An English Version with Supporting Studies, Brill, Leiden 2000); Atenas 2000, dedicado a la Cristología en la teología de San Gregorio de Nisa, cuyas Actas están para aparecer; Olomuc 2004, dedicado al Contra Eunomium II de Gregorio de Nisa y cuyas Actas se publicarán también próximamente.

4 Cfr L.F. Mateo-Seco, Civilización y paidesis en Gregorio de Nisa, en J. Laspalas (ed.), Historia y teoría de la educación. Estudios en honor del Prof. Emilio Redondo, Eunsa, Pamplona 1999, 247-264.

5 Cfr G. Maspero, La Trinitá e l' uomo: l'Ad Ablabium di Gregorio di Nissa, Città Nuova 2004, especialmente pp. 201-266, en las que ofrece un estudio del concepto de persona trinitaria y su influencia en el concepto de persona humana en Gregorio de Nisa.

6 Gregorio de Nisa piensa que el hecho de que el hombre sea imagen de Dios comporta una cierta infinitud: Dios es infinito de hecho; el hombre tiene una capacidad infinita de crecimiento en la virtud. Se trata, pues, de una epéktasis, una ascensión continua y nunca terminada, hacia la perfección. Como escribe A. Spira, «la epéktasis paulina es interpretada por Gregorio como progreso infinito en el sentido filosófico. Las consecuencias de esta nueva concepción de la areté (la virtud) son considerables. Pues al fundamentarse en un movimiento infinito hacia el infinito, Gregorio trasciende la lógica aristotélica, que aborrece todo progreso al infinito. Esta nueva filosofía del infinito —desarrollada, como ha mostrado Langerberk, contra el Dios limitado de Orígenes - ha hecho de Gregorio el inspirador de la mística europea y, por esto, uno de los padres del dinamismo progresista tan característico de nuestra civilización occidental» (A. Spira, Le temps d' un homme selon Aristote et Grégoire de Nyssa, en «Colloques internationaux du CNRS», París 1984, 289 s.)

7 En la Antigüedad clásica, et término parrhesía servía para designar la libertad de expresión, la franqueza, la tranquilidad propia del ciudadano libre en perfecto uso de sus derechos de ciudadanía. Gregorio de Nisa lo utiliza con frecuencia para designar la libertad de una conciencia pura, libre de «miedo» y de vergüenza» (cfr L.F. Mateo Seco, Parrhesía en Diccionario de Gregorio de Nisa, cit., 712-715. 
perspectivas más adecuadas para calibrar las líneas de fuerza de la antropología nisena y su concepto de la naturaleza y de la dignidad del ser personal. ${ }^{8}$

Gregorio trata explícitamente este asunto en muchos lugares. Aquí nos limitaremos a comentar los más importantes: la Homilía IV Sobre el Eclesiastés, el tratado Sobre el origen del hombre, y el Gran discurso catequético.

\section{TRES AXIOMAS}

El pensamiento de Gregorio sobre la naturaleza de la libertad humana y su inseparabilidad de la dignidad personal queda de manifiesto en algunas de sus conocidas frases lapidarias. He aquí algunos ejemplos:

Es por ser dueño de sí mismo (autexousios) como el hombre llega a ser feliz e imagen de Dios (theoeidés), pues el ser dueño de sí mismo y no estar sometido a un dueño es lo propio de quien es señor de sí mismo (autocratés) y carece de dueño (es a-déspotos). ${ }^{9}$

El hombre, creado a Imagen de Dios, debe poseer todos los bienes de su Ejemplar. Ahora bien, entre estos bienes está el hecho de ser libre de la necesidad. ${ }^{10}$

La libertad es el parecido con quien carece de dueño (es a-déspotos) y es soberano de sí mismo (autokratés), semejanza que se nos dio en el principio. ${ }^{11}$

Citas como éstas podrían multiplicarse en gran abundancia, ${ }^{12}$ pero la claridad de pensamiento y de expresión de Gregorio lo hacen innecesario. Por así decirlo, la libertad es la corona de la Divinidad y es corona también del hombre, hecho a imagen y semejanza de Dios. Esta libertad viene concebida en una doble dimensión: ser dueño de sí mismo (autokratés) y no estar sometido a un dueño, es decir, ser a-déspotos. Dicho en lenguaje negativo, es no tener ni necesidad interna, ni coacción exterior.

Este panorama queda destacado aún más por la descripción que Gregorio hace de Dios, al mismo tiempo cercana y correctora del pensamiento de Plotino (cfr Enneadas VI, 8, 13):

Dios, escribe Gregorio, quiere continuamente ser lo que es, y es adecuadamente aquello que quiere ser. ${ }^{13}$

8 El tema ha sido ya lo suficientemente estudiado como para poder ofrecer una visión de conjunto del pensamiento de Gregorio sobre la relación existente entre libertad y dignidad de la persona. Entre otros estudios, cfr. M.M. Bergadá, La condamnation de l' esclavage dans l'Homélie IV, in S.G. Hall (Ed.), Gregory of Nyssa: Homilies on Ecclesiastes, de Gruyter, New York 1993, 185-196; J. Daniélou, La notion de personne chez les Pères grecs, Bulletin des Amis du Card. Danièlou 19 (1983) 3-10; T.J. Dennis, The Relationship Between Gregory of Nyssa's Attack on Slavery in his Fourth Homily on Ecclesiastes and his Treatise De Hominis Opificio, StPatr 17/3 (1982) 10651072; S. Elm, Virgins of God: The Making of Ascetism in Late Antiquity, Clarendon Press, Oxford 1994, 103; J.J. Gaïth, La conception de la liberté chez Grégoire de Nysse, J. Vrin, París 1953; P. Garnsey, Ideas of Slavery from Aristotle to Augustine, Cambridge University Press, Cambridge 1996; P.M. Gregorios, Cosmic Man, Sophia Publications, New Delhi 1980, 133-136; G. Maspero, La Trinità e l'uomo, Città Nuova, Roma 2004, 234-237; R. Moriarty, Human Owners, Human Slaves: Gregory of Nyssa, Hom. Eccl. 4, StPatr 27 (1993) 62-69; D.F. Stramara, Gregory of Nyssa: An Ardent Abolitionist?, SVTQ 41 (1997) 37-60.

9 Gregorio de Nisa, De mortuis, W. Jaeger (ed.), Gregorii Nysseni Opera, IX, 54.

10 Gregorio de Nisa, De hominis opificio, en Patrologia graeca 44, $184 \mathrm{~B}$.

11 Gregorio de Nisa, De anima et resurrectione, Patrologia graeca 46, $101 \mathrm{D}$.

12 Cfr las voces a-déspotos, autexousios, autokrates, en F. Mann (ed.) Lexicon Gregorianum I, Brill, Leiden 1999, 68-69, 618-619 y 621-622 respectivamente. Cfr M. Harl, Problèmes posés par l' histoire du mot autexousios: liberté stoïcienne et liberté chrétienne, «Revue des Études Grecques» (París), 73 (1960) 27-37

13 Gregorio de Nisa, Contra Eunomium III, W. Jaeger (ed.), Gregorii Nysseni Opera, II, 46. 
Esto significa identidad consigo mismo, identidad entre ser y voluntad, es decir, la suprema libertad entendida como eleuthería, como libertas, como trascendencia y amor ${ }^{14}$. Es, por decirlo con brevedad, la libertad del amor con que están unidas entre sí las tres.personas de la Trinidad, es la libertad de Aquel que es Comunión interpersonal y Vida por sí misma, es decir, vida que se autoposee y que se entrega. Gregorio de Nisa es indiscutiblemente uno de los autores del Símbolo de Constantinopla (a. 381), donde se califica al Espíritu Santo como zoopóion, es decir, como dador de Vida.

Nos encontramos ante una afirmación profunda de la trascendencia del Espíritu de Dios y de su identidad consigo mismo. Como escribe J.J. Gaïth, para Gregorio, «todo es por el Espíritu, en el Espíritu, y para el Espíritu. Pero esta trascendencia del espíritu no sería ni absoluta ni independiente si su libertad encontrase oposición por parte de otras libertades, es decir, si pudiesen existir otros dioses independientes y distintos». ${ }^{15}$ De ahí esa doble dimensión de la libertad según el pensamiento patrístico del siglo rv: la libertad de la identidad interior (la autoexousía), y la libertad de toda presión exterior, es decir, el ser a-déspotos. Ambas dimensiones de la libertad se deben reflejar en aquél que está hecho a imagen y semejanza de Dios, es decir, en el hombre. También él debe estar dotado de potestad o dominio sobre sí mismo (autoexousía), y de libertad de coacción exterior, es decir, debe ser a-déspotos, no debe tener dueño. Dicho de otra forma: debe ser idéntico a su diseño original y debe estar libre de todo dueño exterior.

\section{LA HOMILÍA IV SOBRE EL ECLESIASTÉS}

El tema aparece largamente desarrollado en la homilía IV sobre el Eclesiastés, donde Gregorio comenta la frase Poseí esclavos y esclavas $(\mathrm{Eccl} 2,7)$, atribuyendo esta frase a la hinchazón de la arrogancia. Esta expresión, dice Gregorio, se levanta directamente contra Dios, pues esto es atribuir al hombre un poder divino, ya que se constituye en dueño de hombres y mujeres. Las frases de Gregorio debieron resonar con fuerza ante su auditorio.

¿Qué dices? Tú condenas a la esclavitud al hombre cuya naturaleza es libre y dueña de sí misma (eleuthera kai autexousios), y haces una ley contra Dios trastocando la ley de su naturaleza. En efecto, resistiéndote a la ley divina y rechazándola, sometes al yugo de la esclavitud a aquél que ha sido hecho para ser señor de la tierra y para que la dominase. Has olvidado los límites de tu potestad, y que el mandato que has recibido está limitado al señorío sobre los seres irracionales. En efecto, dice la Escritura: Dominad sobre las aves, los peces, los cuadrúpedos y sobre los reptiles $(\mathrm{Gn} 1,26)$. ¿Cómo, olvidándote de los seres que te están sometidos, osas levantarte contra la misma naturaleza libre (eleuthera physis) colocando a tus semejantes entre los cuadrúpedos o los animales carentes de pies? ${ }^{16}$

El rechazo de la esclavitud por parte de Gregorio se fundamenta en tres argumentos de fondo que, de hecho, son universales: la tesis filosófica de la igualdad de la naturaleza humana, la afirmación judeocristiana de que el hombre ha sido creado a imagen y semejanza de Dios, y la convicción de que la libertad es la cualidad más alta del hombre, pues es el rasgo principal de su semejanza con Dios. Digamos inmediatamente que cuando Gregorio habla de Dios está pensando en el modo personal en que Dios existe en su donación, es decir, en la comunión interpersonal entre el Padre, el Hijo y el Espíritu Santo. La libertad, como perfección

14 Sobre la libertad como trascendencia en Dios y la relación entre eleuthería y proáiresis, entre libertad estructural y libertad funcional, cfr J.J. Gaïth, o.c., 15-39.

15 J.J. Gaiith, oc., 24-25.

16 Gregorio de Nisa, Eccl IV: F. Vinel (ed.), Grégoire de Nysse, Homélies sur l'Ecclésiaste, Sources Chrétiennes, París 1996, 226-227. 
que anuda en sí misma la inteligencia y el amor, y que es un reflejo del ser divino en el hombre, es concebida así como lo más estrictamente personal e intransferible: en ella radica el núcleo de la persona, porque en ella radica la capacidad de amar y de entregarse.

El pensamiento de San Agustín, que escribe unos cuarenta años más tarde, muestra hasta qué punto fue fecunda y permanente la concepción de Gregorio de Nisa sobre la relación entre persona y libertad:

En casa del justo (...) sirven también los que mandan a aquellos que parecen dominar. La razón es que no mandan por deseo de dominio, sino por deber de caridad; no por orgullo de reinar, sino por bondad de ayudar. Esto es prescripción del orden natural. Así creó Dios al hombre. Domine, dice $(\mathrm{Gn} 1,26)$, a los peces del mar, y a las aves del cielo, y a todo reptil que se mueve sobre la tierra. Y quiso que el hombre racional, hecho a su imagen, dominara únicamente a los irracionales, no el hombre al hombre, sino el hombre a la bestia. ${ }^{17}$

Nótese que el pensamiento de Agustín es el mismo que el de Gregorio: la cita del Antiguo Testamento es la misma, y la argumentación teorética es la misma. Es el orden natural, la dignidad de la persona, el que exige que no haya «dominio» del hombre sobre el hombre. Esta es la razón de que ante la tiranía de las personas o de las leyes el hombre se sienta agredido en su dignidad personal. La Utopía de Tomás Moro y su concepción de las relaciones humanas tiene tras de sí, pues, una larga tradición y un firme pensamiento. La diginidad del hombre, hecho a imagen de Dios, exige de por sí, por el «orden natural», estar libre de todo dominio y, dado que en la sociedad es necesario el ejercicio de la autoridad, este ejercicio ha de concebirse como un servicio, no como un dominio.

Prosigue Gregorio interpelando a quienes han adquirido esclavos:

Tú, dividiendo la naturaleza humana entre esclavitud y señorío, has hecho que ella sea al mismo tiempo esclava y dueña. Dices, en efecto: He adquirido esclavos y esclavas (Eccl 2, 27). Dime sinceramente: ¿A qué precio? ¿Qué cosa has encontrado en todo lo existente que fuese de igual valor que la naturaleza humana? ¿En cuanto precio has valorado la razón? ¿Cuántos óbolos has pagado por la imagen de Dios? ¿Por cuántos estateres has evaluado la naturaleza creada por Dios? En efecto, dice Dios. Hagamos al hombre a nuestra imagen y semejanza $(\mathrm{Gn} 1,26)$. A aquel que ha sido hecho a semejanza de Dios y que tiene el dominio sobre toda la tierra y que ha recibido de Dios poder sobre todo los seres que están en la tierra (cfr Gn 1,26), dime, ¿quién podrá tasarlo? ¿Quién podrá comprarlo? Sólo Dios puede hacer esto. Más aún; ni siquiera Dios puede hacerlo. En efecto, dice la Escritura: Sus dones son irrevocables (Rm 11, 29). Así pues, ni siquiera Dios podría reducir a esclavitud a la naturaleza humana, Él que libremente nos ha llamado a la libertad cuando éramos esclavos del pecado (cfr Rm 11, 29). Si pues, Dios no reduce a esclavitud a quien es libre, ¿quién osará colocar su propio poder más alto que el de Dios?. ${ }^{18}$

De hecho nos encontramos ante dos argumentos distintos en el rechazo frontal del dominio del hombre sobre el hombre: 1) un primer argumento es la igualdad de la naturaleza humana; 2) Un segundo argumento es que Dios ha entregado al hombre el don de la libertad y jamás la retirará: Él no se arrepiente de los dones que da.

La igualdad de la naturaleza humana, más aún, la unidad de la naturaleza humana es uno de los temas filosóficos más queridos para Gregorio de Nisa. ${ }^{19}$ Los hombres no sólo son igua-

17 San Agustín, La Ciudad de Dios, 19, 14-15: BAC 172, 490-491.

18 Gregorio de Nisa, Eccl 4: F. Vinel, o.c., 228.

19 Cfr L. Turcescu, voz Persona; J. Zachhuber, voces Phyrama (masa) y Physis (naturaleza) en Diccionario de Gregorio de Nisa, cit., 724-733, 733-737, 737-745 respectivamente. 
les en dignidad, sino que la naturaleza humana está unida con tal solidaridad que forma «como un inmenso animal». Esta concepción no puede menos de hacer horroroso cualquier despotismo del hombre sobre el hombre. Cuando eso se da, y se da con frecuencia, semejante desequilibrio no puede menos de ser considerado como una gravísima enfermedad social. Resuenan aquí los ecos de la concepción estoica de la sociedad como un cuerpo en el que hay una gran unidad. ${ }^{20}$

\section{EL PRECIO DE UN HOMBRE}

Gregorio prosigue su argumentación sobre la imposibilidad de pagar un precio justo por un hombre. Las líneas que vamos a citar ahora descansan sobre un principio del Derecho Romano: el precio que se paga por el esclavo no incluye el peculio de aquel que es vendido. ${ }^{21} \mathrm{En}$ consecuencia, para comprar a un hombre habría que comprar el mundo entero, pues Dios entregó al hombre el dominio sobre toda la tierra. He aquí las palabras de Gregorio:

¿Cómo podrá ser vendido aquel que tiene el dominio sobre toda la tierra y sobre todo lo que se encuentra en ella? En efecto, es necesario que los bienes de quien es vendido sean vendidos también. ¿Y en cuánto valoraremos toda la tierra? ¿En cuánto valoraremos todo lo que se encuentra sobre la tierra? Ahora bien; si todas estas cosas no tienen precio, dime, ¿qué precio tendrá aquel que es señor de todas ellas? ${ }^{22}$

Gregorio continúa (era un perfecto retórico) señalando que incluso aunque hubiese capacidad para pagar el precio que vale el mundo entero, ni siquiera así se podría pagar el precio justo por un hombre, ya que cada hombre vale mucho más que el mundo entero, como dijo el Señor (Mt 16, 26). Es ridículo, por tanto, pensar que una «carta», un papel en el que se ha escrito un contrato, convierta a un hombre en dueño de otro. Por mucho que ese contrato diga que eres su dueño, prosigue argumentando irónicamente Gregorio, ese contrato no te hace más fuerte, más hermoso, dotado de mayor salud o de más inteligencia que tu esclavo. Los dolores y las alegrías, los sufrimientos y los placeres, las enfermedades y la muerte afectan por igual al amo y al esclavo. ¿Cómo es posible, pues, que tú pienses que eres superior al esclavo que has comprado? ¿Es que acaso piensas tener en tu poder con igual derecho a esclavos y animales?

En resumen, este lugar la argumentación de Gregorio descansa sobre tres convicciones básicas: 1) La idea filosófica de la unidad de la naturaleza humana existente por igual en todos los hombres; 2) La creación del hombre, destinado a ser señor de la tierra y de los seres irracionales; 3) El hecho de que el hombre ha sido creado a imagen de Dios y que este parecido con Dios consiste principalmente en la libertad, por la que el hombre se constituye en señor de sí mismo. Este último es un rasgo inconfundible y el más personal de la antropología nisena, ${ }^{23}$ y está en estrecha relación con la concepción que Gregorio tiene de la relación entre la persona y el amor: sólo quien es señor de sí mismo puede entregarse con donación personal al amor y a la amistad. Gregorio desarrolla magistralmente esta idea en su comentario al Cantar de los Cantares, donde el amor y el éxtasis dan sentido a toda existencia personal.

20 W. Jaeger, Cristianismo primitivo y paideia griega, Fondo de cultura económica, Méjico 1980, pp. 101-139.

21 Como anota Sandro Leanza, «secundum ius Romanum peculium cum servo non emitur, nisi expressis verbis hoc stipulatum est: Digestum, 18, 1, 29;21, 2, 3». Los bienes del esclavo no entraban en su precio de venta, y eran evaluados separadamente» (S. Leanza (ed.), Gregorio di Nissa, Omelie sull'Ecclesiaste, Città Nuova, Roma 1990, p. 92, nt 13).

22 Gregorio de Nisa, Eccl 4: F. Vinel, o.c., 228-230.

23 Cfr M.M. BERGADÁ, o.c., 195. 


\section{SOBRE LA CREACIÓN DEL HOMBRE}

En el De hominis opificio, escrito el a. 379, Gregorio aborda el tema de la libertad como parte esencial de la persona desde su concepción del hombre como imagen de Dios. A este asunto está dedicado el capítulo 16. El De hominis opificio muestra en sí mismo el amplio conocimiento que Gregorio posee de la cultura clásica. Como señala Laplace ${ }^{24}$ es llamativa la coincidencia de Gregorio con Filón de Alejandría y con Cicerón y, quizás a través de él, con Posidonio. Esta coincidencia, sobre todo con el ciceroniano De natura deorum, da pie a E. von Ivanka a avanzar la hipótesis de que Posidonio sería la fuente común de Cicerón y de Gregorio. ${ }^{25}$ Cherniss ha demostrado también que, en esta cuestión, la influencia de Platón sobre Gregorio es abrumadora. ${ }^{26}$ En cualquier caso está claro que Gregorio se mueve a gusto en el ambiente estoico, optimista desde el punto de vista antropológico. Así sucede en temas como la simpatía universal, el orden del mundo, la grandeza del hombre, el antropocentrismo. ${ }^{27}$

Y sin embargo, ya desde el comienzo del capítulo 16 del De hominis opificio, Gregorio quiere señalar su diferencia con los estoicos. La exaltación del hombre que hacen los estoicos le parece pequeña:

Algunos filósofos paganos han expuesto ideas verdaderamente mezquinas e indignas de su nobleza [del hombre]. Ellos han creído glorificar a la humanidad comparándola con este mundo de aquí abajo. Llaman al hombre microcosmo, compuesto de los mismos elementos que el universo. Con este nombre pomposo ellos han querido hacer el elogio de nuestra naturaleza, pero no se han percatado de que, para ellos, la grandeza del hombre pertenece también a los mosquitos y a los topos. Ellos, en efecto, están compuestos por los cuatro elementos, como todos los seres animados (...) ¿Qué grandeza comporta para el hombre ser la imagen y la semejanza del universo? Según la Iglesia, ¿en qué consiste la grandeza del hombre? No en ser imagen del universo creado, sino en ser imagen de la naturaleza de Aquél que lo ha hecho. ${ }^{28}$

Gregorio admira con los estoicos la armonía y belleza del universo y la grandeza del hombre. Para los estoicos, el hombre es el centro del universo y el fin al que tienden todas las cosas: pero esto no evita que el hombre quede reducido a ser un elemento del universo; para Gregorio, en cambio, el hombre es centro del universo, pero es un centro que, al mismo tiempo, lo trasciende. La trascendencia estriba en que el hombre es portador en su naturaleza de una referencia esencial a Aquél que está por encima del universo. Esto lleva consigo que un hombre, por el hecho de ser hombre, es decir, por el hecho de ser imagen de Dios, vale más que el universo material entero. Su habitat, por así decirlo, es la infinitud.

Así se ve en la aplicación que hace Gregorio en lo que concierne a la relación de la virtud con la libertad. He aquí las palabras de Gregorio:

El hombre ha sido hecho a imagen de Dios (Gn 1,26). Esto equivale a decir: Él ha hecho participar de todo bien a la naturaleza humana. En efecto, si la Divinidad es la plenitud de todo bien y el hombre es su imagen, ¿hay algo en esta plenitud que la imagen no tenga en su semejanza con el arquetipo? Así pues, en nosotros está toda clase de bienes, toda virtud, toda sabiduría y todo lo mejor que se puede pensar. Uno de estos bienes consiste en la libertad que no está sometida a ninguna necesidad, que no está sojuz-

24 Laplace (ed.), Grégoire de Nysse, La creation de l'homme, Sources Chrétiennes 6, París, $20-26$

25 Cfr E. von Ivanka, Die Quelle von Ciceros de natura deorum II, 45-46, «Archivum philologicum», 59 (1935), 10-21.

26 Cfr H.F. Cherniss, The Platonism of Gregory of Nyssa, «University of California Publications in Classical Philology (Berkeley) 11, 1 (1930) 1-92. Cfr Platón, Obras completas, Aguilar, Madrid 1972, 841.

27 Cfr J. Laplace, (ed.) Grégoire de Nysse, La création de l'homme, Sources Chrétiennes, 6, París 1943, 22-23.

28 Gregorio de Nisa, De hominis opificio 16: «Patrologia Graeca», 44, 179-180. 
gada por ningún poder físico, sino que posee el señorío (autexousion) hacia lo que le parece. En efecto, la virtud no está sometida al dominio de nadie (es $a$-déspotos) y es dueña de sí misma y voluntaria (ekousion). En consecuencia lo que se hace por cierta necesidad o por alguna coacción no puede estar en coherencia con la virtud. ${ }^{29}$

El tema de la relación necesaria entre virtud y libertad es platónico; ${ }^{30}$ Gregorio lo ha asumido encuadrándolo en su concepción cristiana del hombre hecho a imagen de Dios. La libertad viene descrita con los adjetivos que nos son ya conocidos y, por supuesto, se opone a la necesidad interna y a la coacción exterior. Gregorio, siguiendo un pensamiento universal en los filósofos clásicos, estima que la virtud perfecciona al hombre en cuanto hombre, es decir, lo perfecciona en su humanidad, en su ser persona. De ahí que sea inseparable de la libertad. Esta libertad se manifiesta y se realiza concretamente en cada elección libre, en cada proáiresis. $^{31}$

\section{EL GRAN DISCURSO CATEQUÉTICO}

La Oratio catechetica magna es una ordenada exposición del pensamiento cristiano dirigida a los catequistas para que sepan dar razón del mensaje que enseñan. Con respecto a nuestro tema, se destacan dos cuestiones: el lugar que el hombre ocupa en el mundo, y la libertad como la característica fundamental de quien está hecho a imagen de Dios.

Gregorio redimensiona aquí lo que ha dicho en el De hominis opificio sobre la visión estoica del hombre como microcosmo. Allí le interesaba defender que el hombre no es una mera síntesis del universo, sino que lo trasciende; no es una imagen del universo, sino una imagen de Dios. En el Gran discurso catequético le interesa recalcar, frente al maniqueísmo, que el hombre ha sido querido por Dios en su corporeidad, y que es imagen de Dios en cuanto ser personal, dotado de libertad. De ahí que insista en que el hombre es síntesis del universo, porque en él la sabiduría divina realiza la unión de lo sensible y de lo inteligible a fin de que lo terrestre sea elevado por su unión en el hombre hasta la esfera de lo divino y, al mismo tiempo, a través del hombre, la gracia se extienda a toda la creación. ${ }^{32}$ En este sentido, el hombre como unión de las dos esferas, espíritu y materia, no es el resultado de una caída anterior, sino de una libre elección divina. Gregorio rechaza así no sólo cualquier tentación de maniqueísmo, sino incluso la posición de Orígenes en torno a la preexistencia de las almas. ${ }^{33}$

En el capítulo quinto, Gregorio avanza hasta dar razón de por qué el hombre ha sido hecho a imagen de Dios. Esto es así, explica, para que tuviera deseo de Dios. El argumento es de gran importancia antropológica: el hombre ha sido creado para participar de los bienes divinos, pero para gozarlos era necesario que sintiese el deseo de ellos, y para que este deseo fuese posible, fue creado con cierta afinidad y parentesco con la naturaleza divina. De ahí que fuese dotado de vida, de inteligencia, de sabiduría y de todos los bienes dignos de la divinidad a fin de que cada uno de estos privilegios le hiciese desear aquello con lo que está emparentado. Entre estos bienes se destaca la libertad.

29 Gregorio de Nisa, De hominis opificio 16: «Patrologia Graeca», 44, 184.

30 Platón, República 617 E.

31 Como anota Dal Toso, «la proairesis es aquella libertad que permite al hombre ser dueño de sí y decidir sobre sí mismo. Tiene una consecuencia práctica, porque permite realizar actos libres. Sobre este aspecto práctico, en cuanto que la libertad permite poseerse y realizarse, se apoya la distinción entre eleutheria, que es ante todo el estado de <<libertad para 〉》 G. dal Toso, voz Proairesis, en Diccionario de Gregorio de Nisa, cit., 757-760.

32 Cfr Gregorio de Nisa, Oratio catechetica magna, 6: Gregorii Nysseni Opera, III/4, $21-22$.

33 Cfr J. Daniélou, L'être et le temps chez Grégoire de Nysse, Brill, Leiden 1970, p. 85. 
Era necesario, dice Gregorio, que Dios dotase al hombre de libertad, y respetase el ejercicio de esta libertad, aún corriendo el riesgo de que esta libertad eligiese el mal:

¿Cómo iba el hombre a ser privado del don más hermoso y más honorable, es decir, el don de ser independiente (a-déspotos) y dueño de sí (autexousios)?. En efecto, si la necesidad determinase la vida humana, en este aspecto, la imagen sería engañosa pues estaría adulterada por una desemejanza con su arquetipo. ¿Cómo podría calificarse de imagen de la naturaleza soberana lo que está sometido y sujeto a ciertas necesidades? Así pues, aquello que ha sido hecho conforme en todo con la divinidad debía con toda seguridad poseer en su naturaleza la libertad (autokratés) y ser independiente (a-déspotos) de forma que la participación en los bienes fuese el precio del combate librado por la virtud. ${ }^{34}$

Los temas nos son ya conocidos. Las ideas son firmes y constantes, y el mismo vocabulario para designar la libertad es utilizado de modo uniforme. En este texto aparece una afirmación que completa lo ya anteriormente dicho: la libertad le ha sido dada al hombre para que la participación en los bienes divinos, la contemplación y el amor, sea el precio del combate ganado por la virtud. Se remacha así la afirmación inspirada en Platón de que la virtud es esencialmente voluntaria y libre y, en consecuencia, que la libertad es un atributo irrenunciable que corresponde al sentido y a la dignidad del ser personal.

Lucas F. Mateo-Seco e-mail:1mateo@unav.es

34 Cfr Gregorio de Nisa, Oratio catechetica magna, 5: Gregorii Nysseni Opera, III/4, 19. Como anota Willing, libertad e independencia son propiedades fundamentales del hombre imagen de Dios. Cfr R. Winling (ed.), Grégoire de Nysse, Discours Catéchetique, Sources Chrétiennes, París 2000, p. 168, nt. 2. 